\title{
Pore-water controlled grain fracturing as an indicator for subglacial shearing in tills
}

\author{
John F. Hiemstra, JaAp J. M. van der Meer \\ Fysisch Geografisch en Bodemkundig Laboratorium, The Netherlands Centre for Geo-Ecological Research (ICG), \\ University of Amsterdam, 1018 VZAmsterdam, The Netherlands
}

\begin{abstract}
Genetic classification of glacial deposits still proves to be highly controversial. In many cases, it remains unclear whether a particular sediment has been subglacially deformed. In the present paper it is suggested that micromorphological research is helpful where current techniques fail to lead to unambiguous interpretations. It is argued that the occurrence of fractured grains in glacial sediments is indicative of subglacial shearing and that such grains may be used as diagnostic evidence of glaciotectonism. Deformational mechanisms associated with the fracturing process are outlined and explained, using a series of thin sections from Wijnjewoude, The Netherlands.
\end{abstract}

\section{INTRODUCTION}

Although knowledge of processes acting in glacial environments has increased considerably over the last two decades (Boulton, 1979, 1987, 1996; Alley and others, 1987; Boulton and Hindmarsh, 1987; Alley, 1989a), the classification of glacigenic sediments still proves to be a problem, especially where the genetic interpretation is concerned (Dreimanis, 1989). In fossil glacial sequences, where different types of diamicton are present, depositional environments are particularly difficult to unravel.

Many investigators of macrostructures have shown that sediments deform under over-riding glaciers (Hart and Roberts, 1994; Benn and Evans, 1996; Menzies and Shilts, 1996). Processes related to this glaciotectonism generally leave a distinct structural signature, providing information which helps to distinguish between subglacial deposits and deposits which have not been affected by glacier ice.

Subglacial deformation eventually tends to homogenize the entire sediment and consequently destroy macroscopically visible evidence. Current research methods often fail to lead to unambiguous interpretation of homogeneous facies and thus conclusions regarding associated processes may not be accurate. In order to gain more insight into subglacial deformation in specific cases, complementary micromorphological analysis is useful. Earlier work (van der Meer, 1987, 1993; van der Meer and others, 1983; Menzies and Maltman, 1992; Bordonau and van der Meer, 1994; Ham and Mickelson, 1995) showed that more detailed observations often lead to the recognition of features indicative of deformation of the sediments. The authors are currently working on a set of diagnostic micro-scale criteria, which can be used to differentiate glacigenic deposits, especially when limited material is available.

In this paper, examples of subglacially deformed sediments are presented, in which the process of grain fracturing is recognized as a major indicator of strain. It is argued that deformational characteristics, like localized fracturing, are typically governed by constraints imposed by subglacial stress conditions and controlled by the specific rheological response of the materials.

\section{DEFORMING BED MODEL}

Van der Meer (1993) suggested that, in order to increase knowledge of subglacial processes, subglacial tills should be described in tectonic, rather than in sedimentary terms. As such, dilation and compaction are assumed to be essential processes acting in a deforming glacier bed (Boulton and others, 1974; Alley, 1989a, b; Murray and Dowdeswell, 1992; Boulton, 1996). Rheological responses of the unlithified sediments are governed by the respective magnitudes of normal loading and shear stresses, as exerted by the moving glacier.

Spatial and temporal changes in water content in the subglacial sediments can be regarded as first-order controls on strain rates. In situations where drainage of subglacially produced meltwater is restrained, high pore-water pressures and consequently low effective pressures develop immediately beneath the glacier sole (Boulton and Hindmarsh, 1987).

\section{Sediment responses}

The yield strength of a subglacial material, which is determined by effective pressure $p^{\prime}$, cohesion $c$ and angle of internal friction $\phi$, increases with depth (assuming that the material has a relatively high permeability) (Boulton and Dobbie, 1993). With respect to the strength, the basal, simple shear stress $\tau_{\mathrm{b}}$, as exerted by the glacier in extensional flow conditions, is assumed to be constant with depth throughout the sediment (Alley, 1989b).

Shear deformation at high strain rates will occur in a layer immediately beneath the glacier sole, where shear stresses exceed local sediment strength. Deformation will 
cease at some depth $z_{\mathrm{a}}$, where the shear stress just equals the yield strength (Boulton, 1996):

$$
\tau_{\mathrm{b}}=\left(p_{0}^{\prime}+z_{\mathrm{a}} \frac{\delta p^{\prime}}{\delta z}\right)(c \tan \phi)
$$

where $p_{0}^{\prime}$ is the effective pressure at the glacier sole. At this depth $z_{\mathrm{a}}$, a time-independent, perfectly plastic type of deformation occurs.

The tectonic "A horizon", thus defined, in which shear stresses and normal loading pressure tend to be accommodated by a subtle interplay between compaction and dilation (Boulton and others, 1974), is underlain by a much denser, consolidated "B horizon".

Towards the base of the A horizon, deformation does not pervade the material equally but tends to be more discrete, and strain rates are significantly lower than in the top part; failure will concentrate in well-developed zones of shear displacement. Theoretically, these shear zones can be regarded as a combined result of uniaxial shortening (compaction, dilatant behaviour being suppressed), and an actual lateral displacement provided by progressive, simple, basal shear.

In the first deformational increments, the failure behaviour of the sediment under these arbitrary brittle-shearing conditions is described mathematically in the failure envelope of Equation (2).

$$
\frac{\sigma_{1}{ }^{\prime}-\sigma_{3}{ }^{\prime}}{2}-\frac{\sigma_{1}{ }^{\prime}+\sigma_{3}{ }^{\prime}}{2} \sin \phi-c \cos \phi=0
$$

where $\sigma_{1}^{\prime}$ and $\sigma_{3}{ }^{\prime}$ represent the largest and smallest principal effective stresses, respectively. Note that, in order to understand stress transmission in any Cartesian frame of reference, "field stresses" are often transformed and projected into a rotated frame, in which principal stress components are known.

Initially, riedel shears are generated at angles which are determined by the respective orientations of the principal stresses. In a passive propagation through sets of successive riedel shear stages, strain is "rotated" towards the actual shearing orientation and eventually localizes in discrete sub-parallel displacement shears (Morgenstern and Tchalenko, 1967; Morrow and Byerlee, 1989; Rajlich, 1993).

\section{Fracturing of grains}

Within diamictons, grain fracturing is to be expected predominantly in zones where dilatant strain behaviour is inhibited by high confining ice pressures (Boulton and others, 1974; van der Meer, 1993). A prerequisite for the fracturing process is direct contact between grains, at which tensile stresses are induced by loading compression and enhanced by shear compaction. Initiation and propagation of fractures are best described in the model of "Hertzian fracture mechanics" (Johnson, 1985). A precondition of the process initiation is the existence of flaws on the grain surfaces, inherited from weathering or transport (Whalley and Krinsley, 1974; Mahaney and others, 1988).

Maximum tensile stresses $\tau_{\mathrm{T}}$ in a grain loaded diametrically occur at the edge of the "contact circle". Fracturing will be initiated if pre-existing flaws at this point develop into cracks when $\sigma_{\mathrm{T}}$ exceeds local cohesive strength of the grain lithology (Brzesowsky, 1995). Failure of the grain occurs when the stress intensity factor, $K_{\mathrm{I}}$, exceeds fracture toughness $K_{\mathrm{IC}}$, as determined by the initial flaw dimension $C_{\mathrm{f}}$ (Equation (3)):

$$
K_{\mathrm{IC}}=a \sigma_{\mathrm{T}} \sqrt{\pi C_{\mathrm{f}}}
$$

(e.g. constant $a=1.12$ for quartz).

In general, fracturing of grains depends on critical stress balances governed by elastic moduli and surface characteristics of the grain material, and is inversely related to the porosity of the sediment, which determines an inflection point beyond which the process of grain fracturing is accelerated (Zhang and others, 1990).

\section{METHODOLOGY}

\section{Sample selections}

The samples described in this paper were collected at Wijnjewoude, The Netherlands, and Kronsberg, Germany. It has been established (Rappol and others, 1989; Höfle, 1983) that the thin sections come from Pleistocene diamictons of subglacial origin. Solheim (1991) illustrated that cores sampled from the northern Barents Sea (Bråsvellbreen, Svalbard), here referred to as samples from "tide-water" settings, are in fact Holocene diamictons affected by a glacier surge.

For the purpose of this study, information regarding the large-scale characteristics of the respective settings was used to relate observed micromorphological structures to deformation caused by over-riding ice and to rule out other sources of deformation.

\section{Procedures}

The samples were impregnated with unsaturated polyester resin and subsequently prepared into thin sections according to techniques described by Murphy (1986) and van der Meer (1996). Observations comprise qualitative analyses using optical transmission microscopy at magnifications ranging from $4 \times$ to $32 \times$. The terminology used to describe the observed features is consistent with pedological nomenclature suggested by Brewer (1976).

\section{OBSERVATIONS FROM THIN SEGTIONS}

When describing subglacial deposits, a relation between texture and angularity of particles is often observed. In general, angularity increases with decreasing particle diameter, a feature which is usually interpreted as a result of abrading processes at the glacier-bedrock interface (Boulton, 1979). From studied thin sections, however, a new line of evidence is presented, in which grain fracturing is related to intrinsic sediment deformation. Tracings of several thin sections show products of grain-fracturing being arranged in specific patterns. Samples from both "terrestrial" and "tide-water" settings were found to exhibit narrow, horizontal or sub-horizontal zones in which the concentration of fracturing products was significantly higher than in the rest of the sample (Fig. 1).

Caution is needed in suggesting that a particular grain has been fractured, as the process of grinding during making the thin section might introduce an artificial type of crushing of skeleton grains, predominantly along their edges (Fig. 2a) or in zones of poor impregnation (Fig. 2b). Criteria for the recognition of fracturing should, therefore, be strict. In order to rule out any confusion with "secondary 


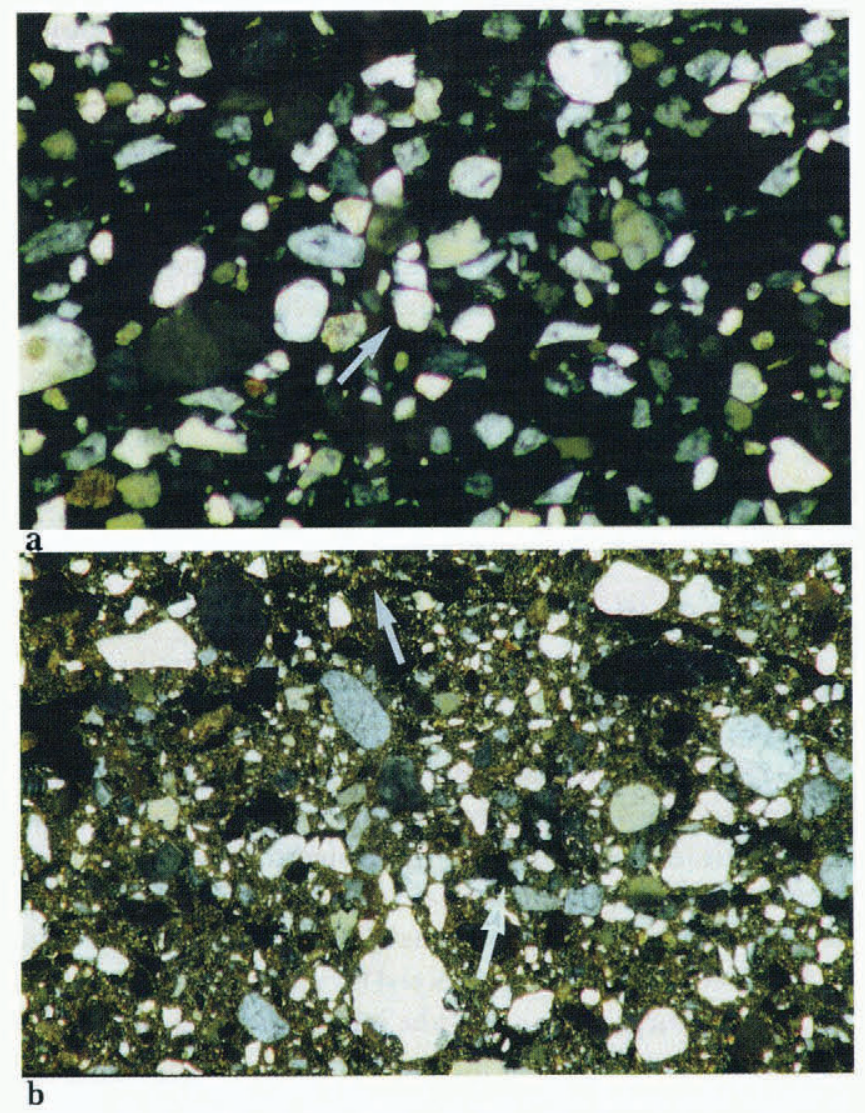

Fig. 1. (a) Grain-supported zone in subglacial till, showing both angular, fractured grains and rounded, intact grains. Note in-situ fracturing, indicated by arrow. Detail of Mi.512; Kronsberg, Germany; cross-polarized light; field of view: $3.5 \mathrm{~mm}$; (b) Matrix-supported till, showing narrow, (sub)-horizontal planes (indicated by arrows) in which angular, fractured grains are lined up. Away from the planes, grains tend to be "intact". Detail of Mi.511; Kronsberg, Germany; cross-polarized light; field of view: $7.0 \mathrm{~mm}$.

processes", we only consider a grain to be fractured when the grain fragments remain "juxtaposed" and edges can be matched. The components are required to show some degree of displacement, witnessed by a "slip" (fracture-parallel displacement; Fig. 2c) or a slight relative rotation (Fig. 2d). In matrix-supported sediments, an infill of matrix material within the fracture is considered sufficient evidence to assume this particular fracture is a primary (i.e. subglacially generated) feature (Fig. 2e).

The best evidence that grain fracturing is a result of subglacially induced sediment deformation is provided by a series of thin sections from Wijnjewoude, The Netherlands. Samples R.971-R.974 were taken from a vertical profile in Saalian till, at depths of 1.68, 1.78, 1.98 and $2.32 \mathrm{~m}$ (van der Meer, 1996, fig. 12.3).

Tracings of the thin sections exhibit a remarkable correlation between the void pattern and the position of fractured grains (Fig. 3). The number of fractured grains seems to display a decreasing trend from top to bottom. In the profile, the uppermost thin section (R.97l) contains the most affected grains but, because of the relatively thin grinding of the sample, not every observed damaged grain could be selected as being a primary fracturing product.

The structure in the profile is highlighted by planar voids, arranging the till aggregates, which appear to be angular towards the bottom (Fig. $4 \mathrm{a}$ ), and rounded in the high- er parts (Fig. 4b). Most of the fracturing takes place at, or in close proximity to, voids, as exemplified in Figure $4 \mathrm{c}-\mathrm{e}$.

This fracturing recognized in thin sections illustrates different types of failure modes. Most of the grains exhibit straight, transgranular cracks (Fig. 5a) or divergent cracks (Fig. 5b), both initiated in the contact zone of grains "in collision". Occasionally, the process of fracturing results in "crushing" of part of the grain (Fig. 5c) or the "chippingoff" of a flake from the grain surface (Fig. 5d).

\section{DISCUSSION}

In the discussion an attempt is made to link observed features to the deforming bed model (Boulton and Hindmarsh, 1987) and to currently held theories on grain fracturing (Johnson, 1985). Although evidence of fracturing has been observed in thin sections from a number of different locations, the "Wijnjewoude" series illustrates the suggested relationships most clearly.

The samples of the "Wijnjewoude" series exhibit an internal structure, which has been called a "marble bed" structure (van der Meer, 1987, 1993, 1996). The aggregation of the till is highlighted by a void pattern, continuous or discontinuous, reflecting an arrangement of planes of weakness in the profile.

\section{Deformation styles}

It is argued that the arrangement is a primary feature and that the location of the voids has been governed by subglacial processes. The structure originates in the lower regions of the deforming layer, towards the transition between the A and B horizons, where discrete shearing is the dominant type of failure. The development of the structure is depicted in Figure 6.

Initially, the subglacial sediment accommodates exerted ice pressures by compression, a situation in which water is expelled. Brittle failure will occur by displacement along well-developed, horizontal or sub-horizontal planes (Fig. 6a).

Most of the applied strain is focused in the prevailing sub-parallel-oriented displacement planes, which may merge and link into continuous networks (Ramsay, 1980). The remaining strain is taken up in intersecting, smallerscale planes (Menzies and Shilts, 1996). The latter shear localization is predetermined by sets of riedel shears, representing defects which are only of secondary significance, but can be traced in the thin sections after brecciation of the till (Fig. 4a) (Morrow and Byerlee, 1989).

In the top of the profile, the voids delineating the aggregates display a curvilinear character, marking a subrounded, circular to ellipsoid aggregation (Fig. 4b). It seems that the edges and corners have been susceptible to adaptation of shape. The roundness of the aggregates suggests a rotational movement in a compound packing, which resembles movement as in a bed of marbles (van der Meer, 1996), a situation corresponding to stage (b) in Figure 6. The gradual transition from angular to rounded aggregates (Figs 3 and $4 \mathrm{a}, \mathrm{b}$ ) reflects a change in strain rates in the deforming layer. The authors suggest that the top section of the profile experienced progressively higher shear stresses, tending towards a more pervasive type of deformation, which eventually resulted in the rotational movement.

The brittle character of the deformation in the material is evidenced by the fact that the interior of the aggregates 

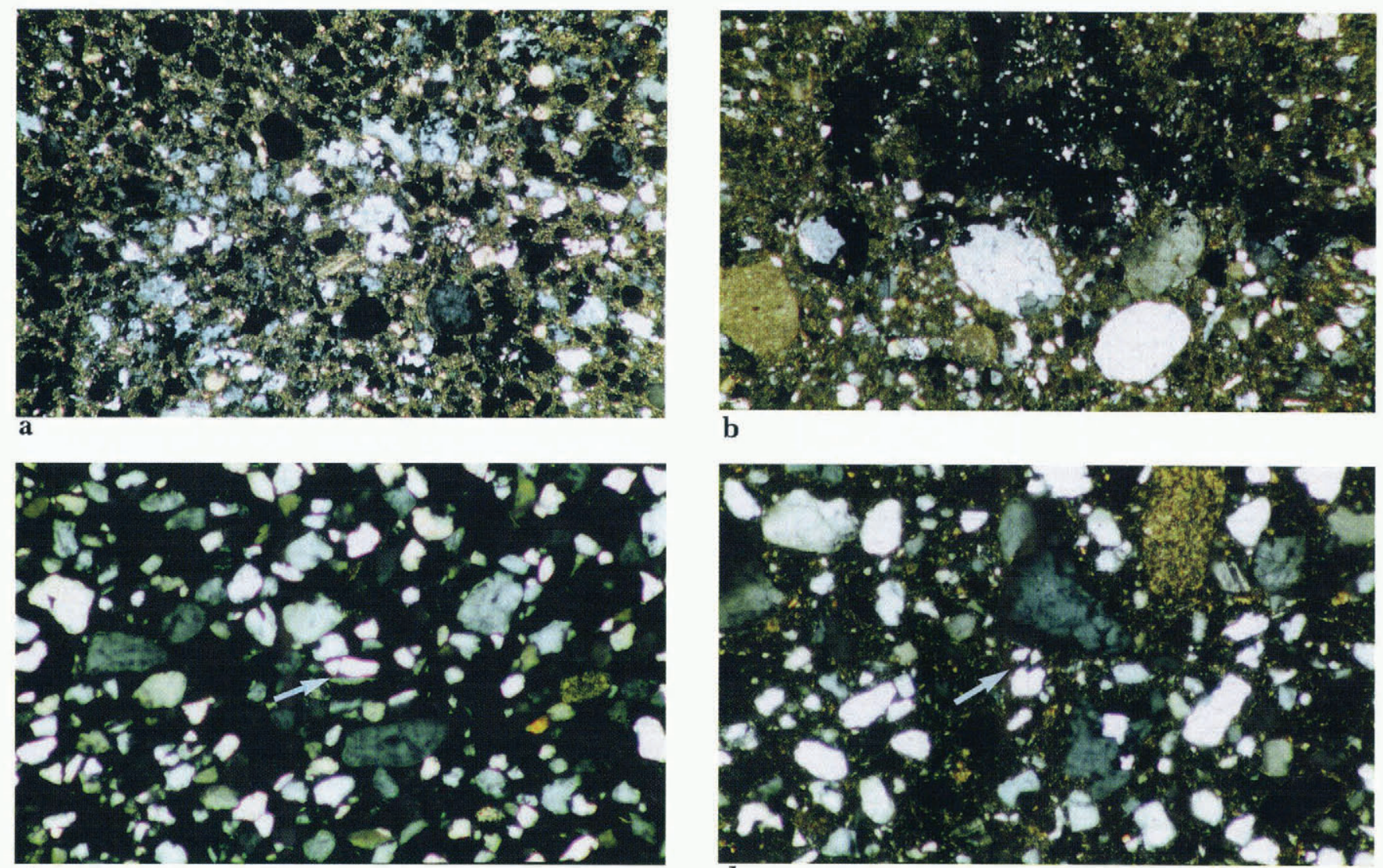

b
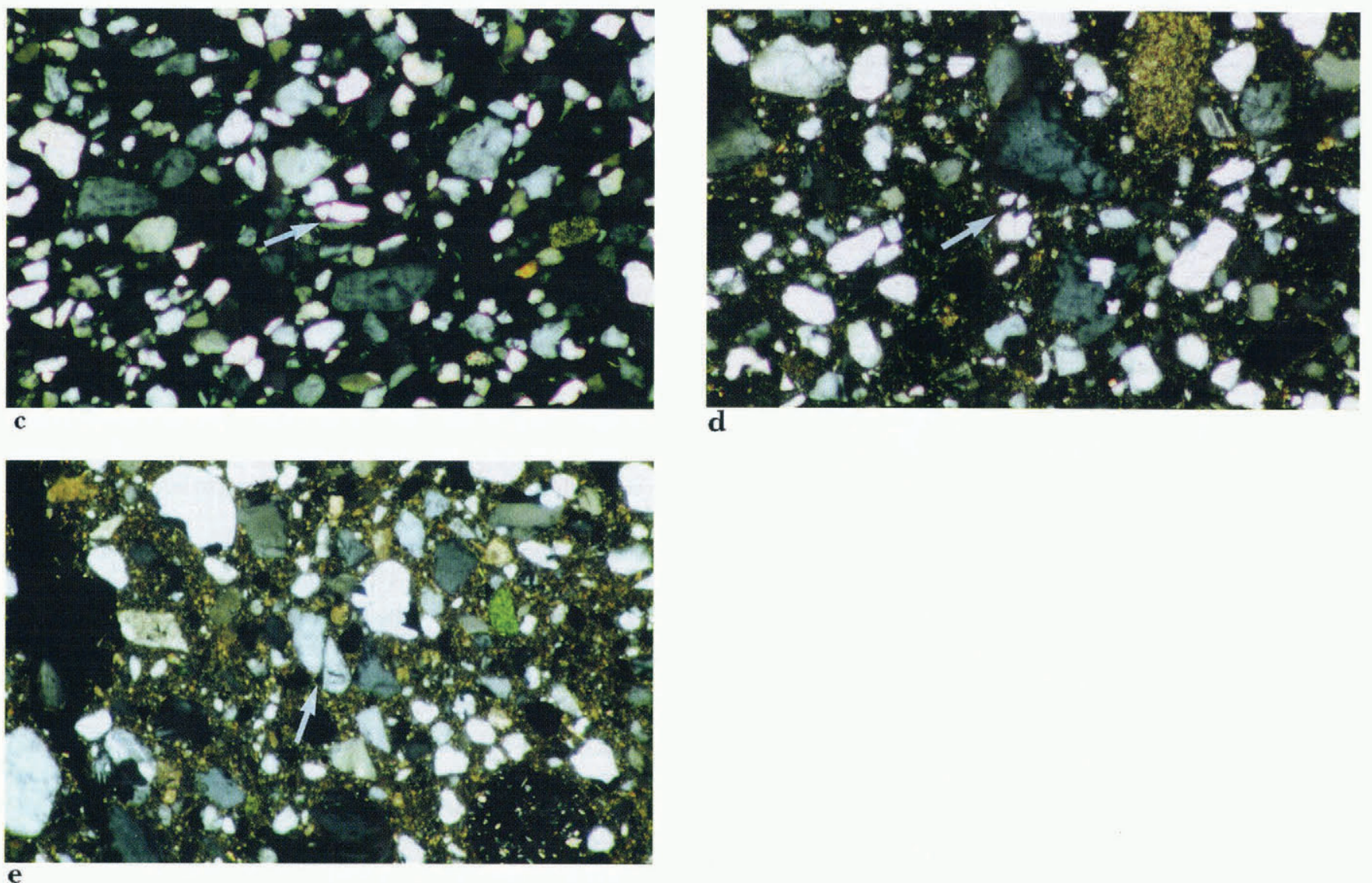

Fig. 2. Applied fracturing criteria. (a) Artificially induced grain fracturing by grinding, witnessed by removed or completely crushed grains along the edges of the thin sections. Detail of R.974; Wijnjewoude, The Netherlands; cross-polarized light; field of view: $5.6 \mathrm{~mm}$. (b) Artificial type of cracking due to incomplete resin-impregnation, causing part of the sample to be distorted during thin-section preparation. Detail of Mi.511; Kronsberg, Germany; cross-polarized light; field of view: $5.6 \mathrm{~mm}$. (c) The grain indicated displays slip of the fracture products along the meridional fracture plane. Displacement indicates that cracking evolved prior to "fixation" by impregnation. Detail of Mi.512; Kronsberg, Germany; cross-polarized light; field of view: $3.5 \mathrm{~mm}$. (d) Edges of the fracture products of the grain indicated can be matched, although the components have completely lost their coherence. Detail of R.972; Wijnjewoude, The Netherlands; cross-polarized light; field of view: $3.5 \mathrm{~mm}$. (e) Components of indicated grain show displacement along fracture. Supporting evidence for "primary" fracturing is obtained from intrusion of plasma into fracture plane. Detail of R.973; Wijnjewoude, The Netherlands; cross-polarized light; field of view: $3.5 \mathrm{~mm}$.

appears rather undeformed. The deficiency of turbates (circular, rotational structures (van der Meer, 1993, fig. 24)) and the poor development of internal plasmic fabric, denoting the birefringence of the plasma (optical property of zones with a preferred clay orientation (Brewer, 1976); both indicate conditions of low ductility in the deforming sediment.

With progressive, simple shearing, additional strain cannot be converted by further compression. At this stage, the rheological response of the material is characterized by dilation (Murray and Dowdeswell, 1992). Aggregates are forced to slide and roll over each other, consequently in- creasing the pore volume. As a result of negative pore pressures, water is again drawn back into the sediment. It should be noted that dilation in this case does involve modification of the till structure (Fig. 6c) rather than interaction between individual grains (Boulton and others, 1974; Hooke and Iverson, 1995).

The dilated structure collapses if strain rates are insufficiently high and a situation similar to stage (d) is created. Higher water contents in the compound material are reflected in the intergrown nature of some of the aggregates. The latter observation may also establish that fissilities and 


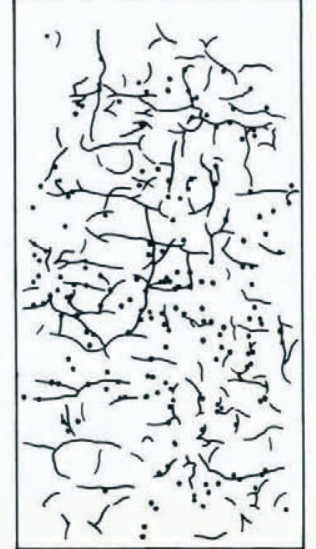

R. 971

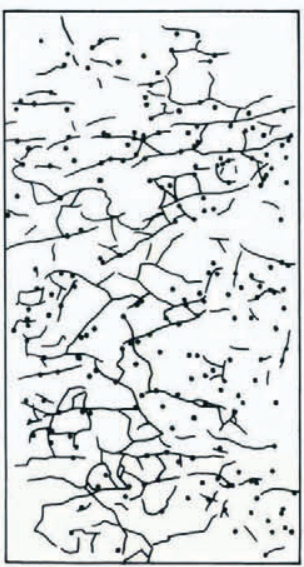

R. 973

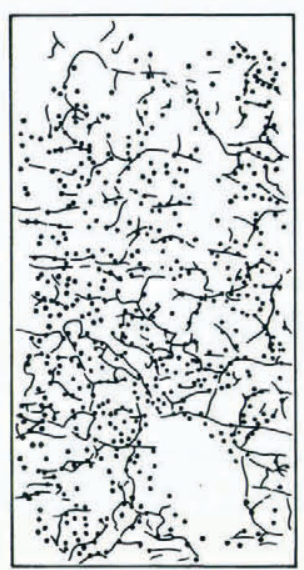

R. 972

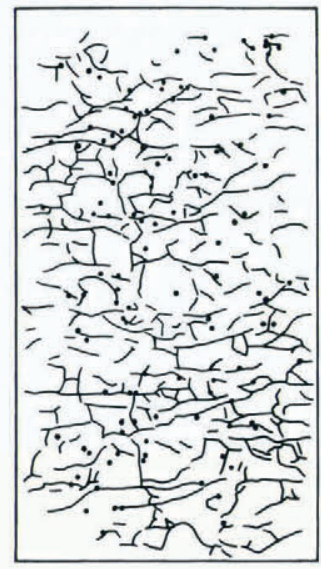

R. 974
Fig. 3. Tracings of thin sections R.971-R.974 from Wijnjewoude, The Netherlands, showing the high correlation between void pattern and the position of fractured grains, as well as the decrease in fractured grain density with depth. Continuous and discontinuous lines represent voids delineating structural units (till aggregates). Dots represent fractured grains. The scale represents $4 \mathrm{~cm}$.

dilated regions act as major preferential conduits for meltwater (van der Meer, 1987).

Persistent shearing of the sediment will again generate compression (stage (a)). A new deformational cycle is initiated with expulsion of water and a process similar to the one described above will evolve.

\section{Towards fracturing}

A high correlation between the location of fractured grains and the void pattern is evident throughout the profile (Figs 3 and $4 \mathrm{c}-\mathrm{e}$ ). It can be established visually that nearly all comminutive action occurs along planes where discrete shear displacement and rotational movement are to be expected. The observed downward decrease in number of fractured grains may well be accounted for by the decreasing deformational "impact" towards the base of the "A horizon".

It is argued that dilation tends to minimize the process of grain fracturing. An increase in pore volume, which is inherent in the dilation mechanism, results in subglacial meltwater entering the fracture planes, thus reducing the yield strength of the compound material. The process thus reduces effective pressures due to relatively high pore-water pressures. Contact between the aggregates is less frequent and friction as a result of grinding is diminished. Collision of grains, situated at the edges of the pebbles, is less likely to happen and, if it does, the resulting contact stresses are generally insufficient to cause the grains to fracture.

Because of the cyclicity in the rheological response to shear stresses, the fracturing process attains an intermittent character. Fracturing observed in the profile is related to conditions following collapse of dilated structures, which causes the material to stiffen (Alley, 1989b). The compression results in an optimum in the fracturing process, because additionally induced shear mobilization is accommodated by a rotational "marble bed" movement of the till aggregates, similar to a cataclastic flow on the scale of individual skeleton grains (Menéndez and others, 1996). Aggregates will re-arrange in a closed-packing configuration until they are stabilized and further movement is inhibited by the normal loading, which accounts for the "lock-up" in a metastable equilibrium (Fig. 6d).

\section{Fracturing styles}

The comminution of skeleton grains in tills involves both "crushing" and attrition, a process commonly known as abrasion. The type of grain failure that occurs in specific subglacial conditions depends on morphology of the grain and its texture. Experiments have shown that particles smaller than coarse silt are mechanically relatively stable (Haldorsen, 1981) and that the highest intergranular stresses occur when grains of similar diameters are in contact (Sammis and others, 1987).

Another factor governing fracture is whether contact loading occurs diametrically or tangentially. When stresses act diametrically, i.e. when the direction of contact loading coincides with the imaginary line connecting the centres of the grains in contact, failure often involves the type of fracturing described by Brzesowsky (1995). Determined by positions of pre-existing zones of weakness (surface flaws), and dependent on compression rates, fractures propagate from the initially plastically deformed contact region, either as divergent cone cracks (Figs $5 \mathrm{~b}$ and $7 \mathrm{a}$ ) or as radial, penetrative meridional cracks (Figs $5 \mathrm{a}$ and $7 \mathrm{~b}$ ).

A further type of fracturing results from shear loading, which induces frictional sliding at the grain-contact surface (Menéndez and others, 1996). This "crushing" into small equidimensional angular elements exemplifies the process of attrition, which is enhanced by tangential loading. The tensile-stress concentration at the trailing end of the sliding-contact region accounts for the crushing of part of the grain (Figs 5c and 7d), or for the "chipping-off" of flakes from the grain surface (Figs $5 d$ and $7 c$ ). The mode of fracturing in the case of tangential loading is influenced by the "angle of incidence" of the contact stress with respect to the line connecting the centres of the grains.

\section{Stress conditions}

In order to quantify subglacial stress conditions during grain fracturing, the authors have attempted to specify a range of critical effective pressures in which the process may be initiated. Estimates are based on a series of laboratory experiments (Morrow and Byerlee, 1989; Zhang and others, 1990; Brzesowsky, 1995; Menéndez and others, 1996), which involved triaxial compression tests, and investigations of hydrostatic compaction behaviour and micro-me- 

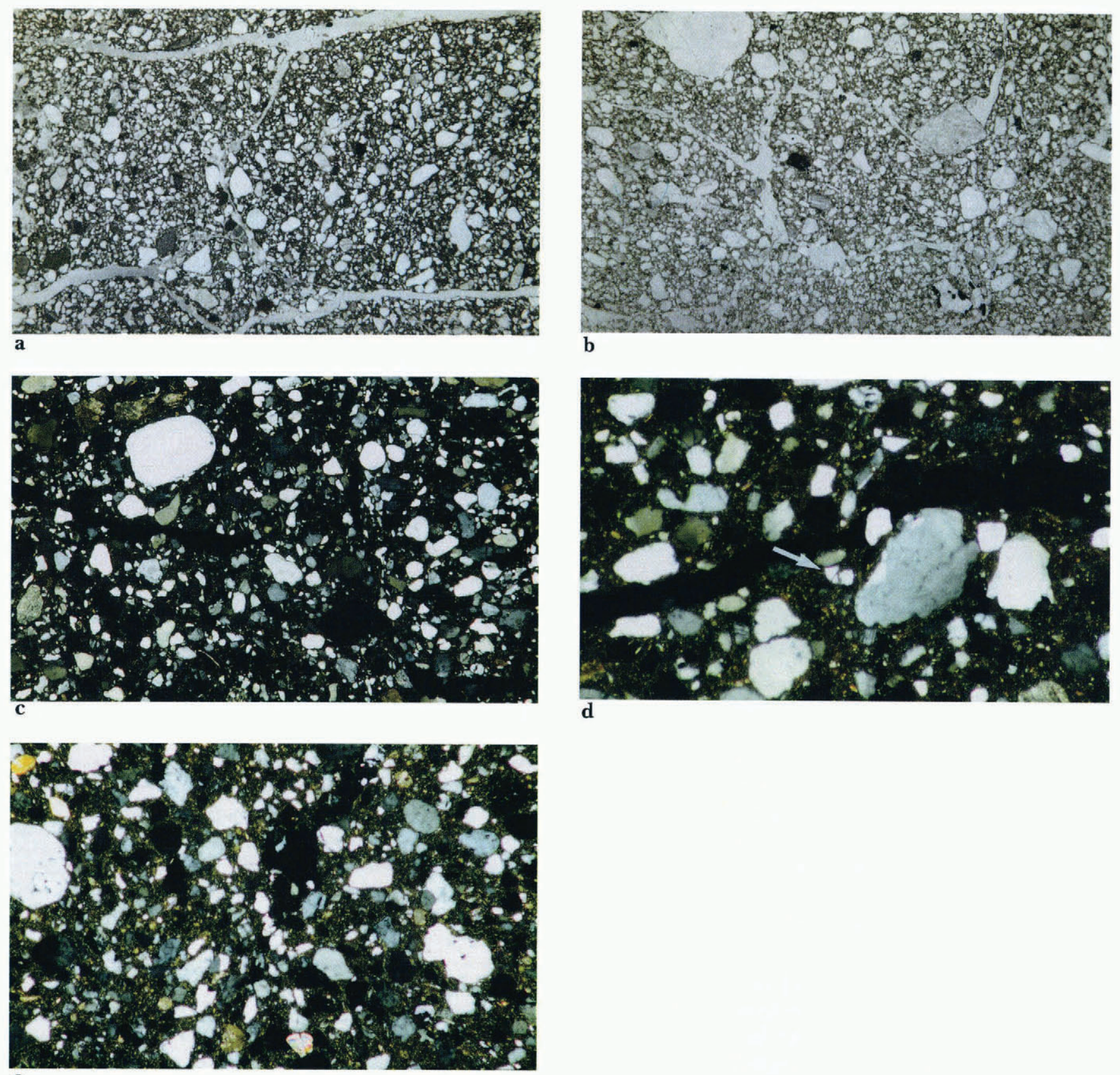

$\mathbf{e}$

Fig. 4. Correlation between grain fracturing and structural voids. (a) Photograph showing the angular structural elements in the lower part of the Wijnjewoude profile. Detail of R.973; Wijnjewoude, The Netherlands; plane light; field of view: $18.0 \mathrm{~mm}$. (b) Photograph from the higher part of the Wijnjewoude profile, showing well-rounded till aggregates. Detail of R.971; Wijnjewoude, The Netherlands; plane light; field of view: $18.0 \mathrm{~mm}$. (c) Significantly higher concentration of angular grains in the proximity of a planar void. Detail of R.972; Wijnjewoude, The Netherlands; cross-polarized light; field of view: $9.0 \mathrm{~mm}$. (d) Evidence of insitu fracturing of the grain indicated, situated close to plane. Detail of R.973; Wijnjewoude, The Netherlands; cross-polarized light; field of view: $3.5 \mathrm{~mm}$. (e) Higher proportion of rounded, intact grains away from voids. Detail of R.973; Wijnjewoude, The Netherlands; cross-polarized light; field of view: $5.6 \mathrm{~mm}$.

chanical failure of sediments. Although the thin sections examined in our study consisted of samples of unlithified diamictons, rather than lithified, porous materials as used in some of the tests, the results can be used to give an indication of the stress range involved in fracturing.

It should be noted that, when trying to match the sediment properties of the thin-section samples with the experimental variables, the commonest constituent in the investigated tills is quartz, with an average grain radius of about $0.15 \mathrm{~mm}$. Lithified test materials with the same characteristics and a porosity of around $25 \%$ yielded a range of effective pressures of $300-380 \mathrm{MPa}$ for the onset of grain fracturing (Zhang and others, 1990). These values were in agreement with predicted theoretical values using the "Hertzian fracture model", where characteristic quartz values for initial flaw dimensions, fracture toughness, Poisson ratio and elastic modulus were used.

Morrow and Byerlee (1989) and Brzesowsky (1995) carried out experiments on unimodal, essentially unlithified, granular sediments and found that fracturing was initiated at significantly lower values of effective pressure (15$75 \mathrm{MPa}$ ). Although test materials used in these experiments are much more realistic, "translations" to field situations remain hypothetical, since it may well be that the specific tex- 

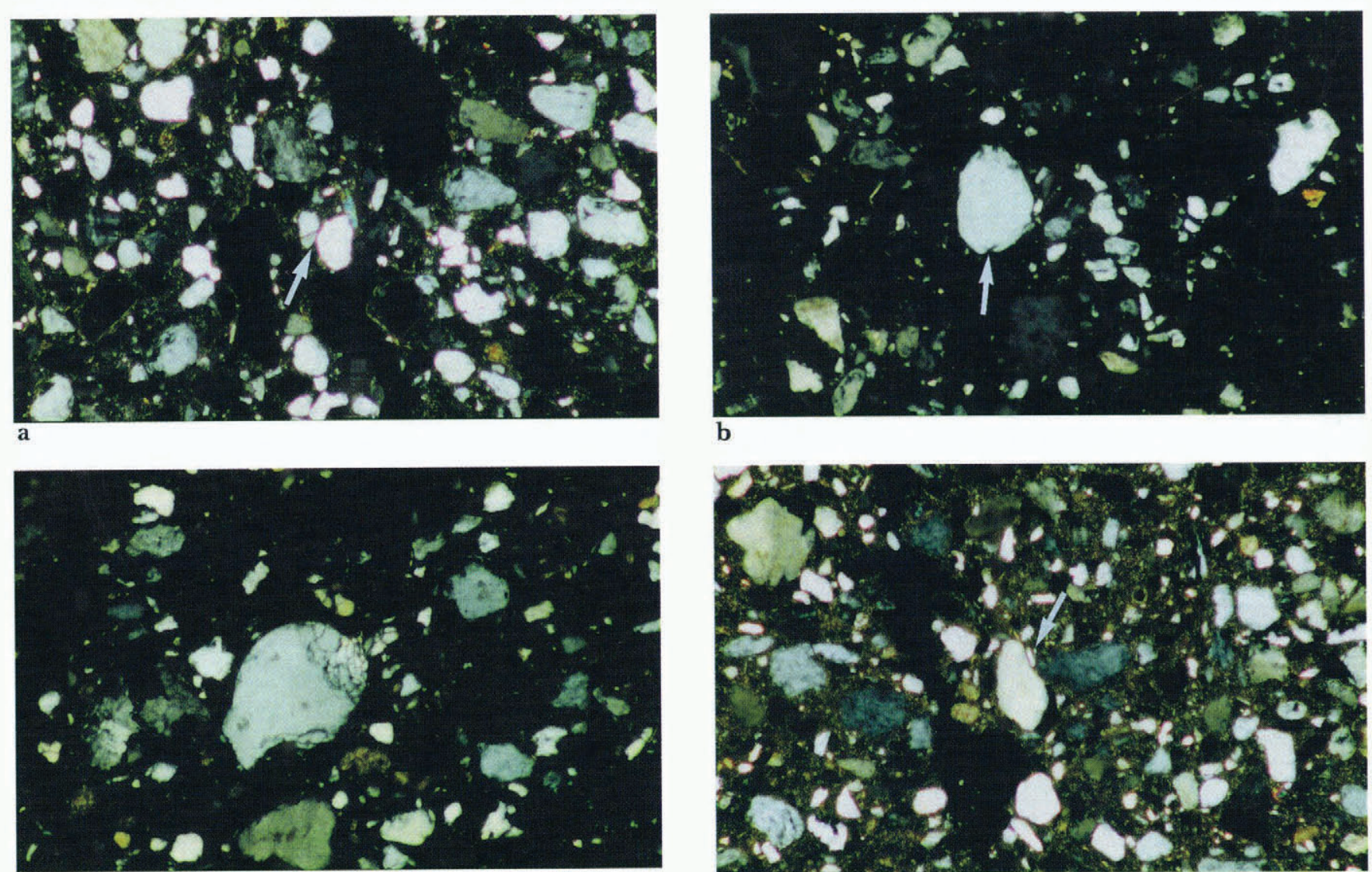

b

c

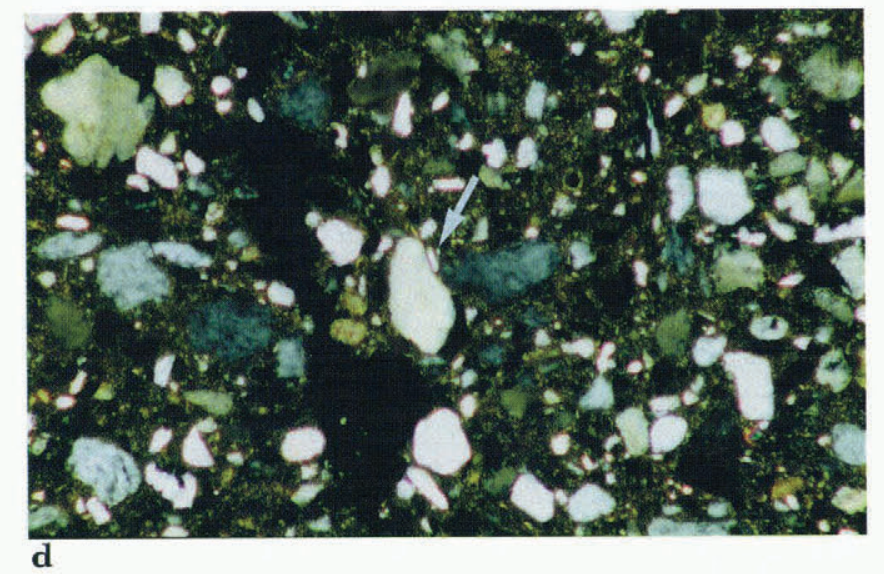

Fig. 5. Types of fracture. (a) Most commonly encountered transgranular fracture. Diametrically colliding grains give rise to propagation of meridional cracks from the contact area (arrow). Detail of R.971; Wijnjewoude, The Netherlands; cross-polarized light; field of view: $3.5 \mathrm{~mm}$. (b) "Ring cracks" at the edge of contact area developed into divergent cone fractures (arrow). Also resulting from diametrical stress. Detail of R.971; Wijnjewoude, The Netherlands; cross-polarized light; field of view: $3.5 \mathrm{~mm}$. (c) Rare "crushing" of part of the grain ascribed to tangential loading. Detail of R.974; Wijnjewoude, The Netherlands; crosspolarized light; field of view: $3.5 \mathrm{~mm}$. (d) Flake has been "chipped" off the grain surface (arrow) under tangential loading. Detail of Mi.511; Kronsberg, Germany; cross-polarized light; field of view; $4.5 \mathrm{~mm}$.

tures (Sammis and others, 1987; Zhang and others, 1990), packing configurations (Hooke and Iverson, 1995) and even pore-fluid compositions (May, 1980; Brzesowsky, 1995) account for accelerated kinematics regarding grain-fracture initiation.

Grain-size distributions within strained materials are shown to change with progressive shearing (Iverson and others, 1996), so governing the type of comminution. Initially, grains may form "networks" to support exerted stresses. In this situation, the relatively small number of contacts between the grains of similar size favour "meridional" fracturing. As a result of this process, larger grains are surrounded by smaller ones, so distributing stresses over more contacts and homogenizing the stress fields. Comminution in the newly formed packing configuration predominantly involves attrition as a result of frictional sliding of grains. It has been shown that critical stress values needed to initiate fracturing changes according to grain-size evolution.

The specified range of $15-380 \mathrm{MPa}$ for onset values is rather wide but this possibly reflects the differences in intrinsic transmission of externally applied forces. It seems plausible that locally developed contact stresses are determined by textural heterogeneity. Furthermore, these local intrinsic stresses are likely to exceed average effective stresses, suggesting that relatively "low" field stresses can initiate the fracturing process.

\section{CONCLUSIONS}

It is evident from the generally angular grains within subglacial sediments that the process of grain fracturing is widespread. However, undisputed evidence is not easily seen in most sediments, because of the instantaneous incorporation of crushing products in a mobile and ductile matrix, especially where attrition is concerned.

The samples from the "Wijnjewoude" profile have provided an opportunity to study the in-situ fracturing of grains. Shear induced in subglacial conditions by an overriding glacier resulted in brittle failure of the sediment, evidence of which is displayed in the preserved aggregation structure. Strain is focused along discrete planes. In the compressive stages of the rheological response to the exerted shear, grain fracturing is initiated in the contact planes between the aggregates. The intermittent character of the fracturing is a response to the suggested cyclic process of deformation, governed by alternating dilation and "stiffening" of the sediment. Displacement in the material, following the final stage of fracturing before conservation, can be assumed to be minimal. "Primary fracturing", according to our definition can readily be identified because individual grain components show some displacement after the fracturing but remain juxtaposed, so that edges can be matched and grains can be "reconstructed" into their intact form.

From the evaluations made in this study, some implic- 


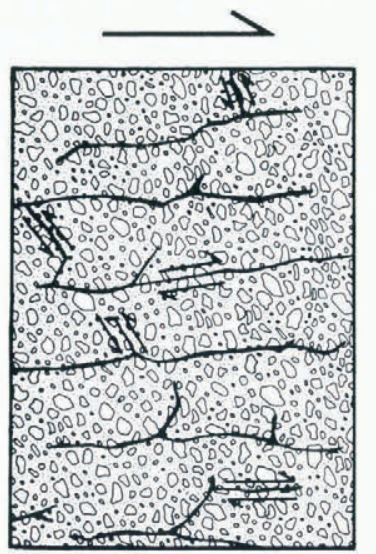

a
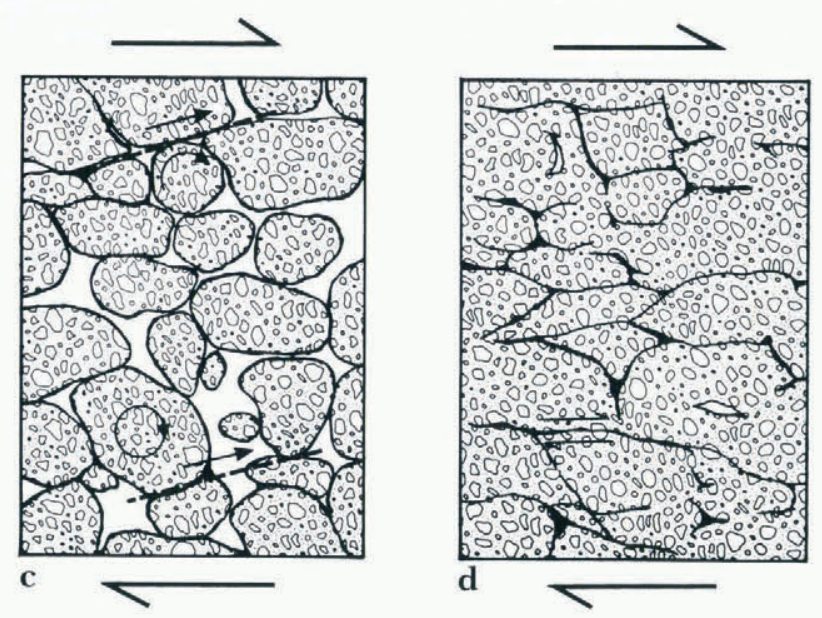

Fig. 6. Cartoon depicting the rheological response to exerted stresses of a texturally homogeneous, fine-grained till. (a) Shear-zone development in response to application of shear stresses after dissipation of water. The displacement has occurred along discrele planes. Strain hardening has permitted some grain fracturing to occur, predominantly along the subhorizontal planes. (b) Brecciation of the dry till accounts for aggregation and progressive shear initiates "marble bed" movement. Rotation of till aggregates in combination with limited pore space results in high effective pressures and optimum conditions for the fracturing process to occur. (c) Additional strain causes the till to dilate; the sediment is forced to expand, subglacial meltwater enters the voids, thus reducing contact stresses. Hardly any grain fracturing has taken place. (d) Collapse of the dilated configuration when strain in the material is not sufficiently rapid. Expulsion of pore water "stiffens" the material and the aggregates become blocked in a metastable configuration. The shear stress exerted may trigger another stage of shear displacement and a situation as in $(b)$ may be generated.

ations of the presence of fractured grains and the role of subglacial pore water in the fracturing process are better understood. The suggested relationship between dilation and grain fracturing (Zhang and others, 1990; Hooke and Iverson, 1995; Iverson and others, 1996; Menéndez and others, 1996) has been established for subglacially deformed tills, by visual correlation in the investigated thin sections.

The authors have demonstrated that grain fracturing is a common feature in zones of brittle-shear displacement and suggest that, considering the specified range of effective
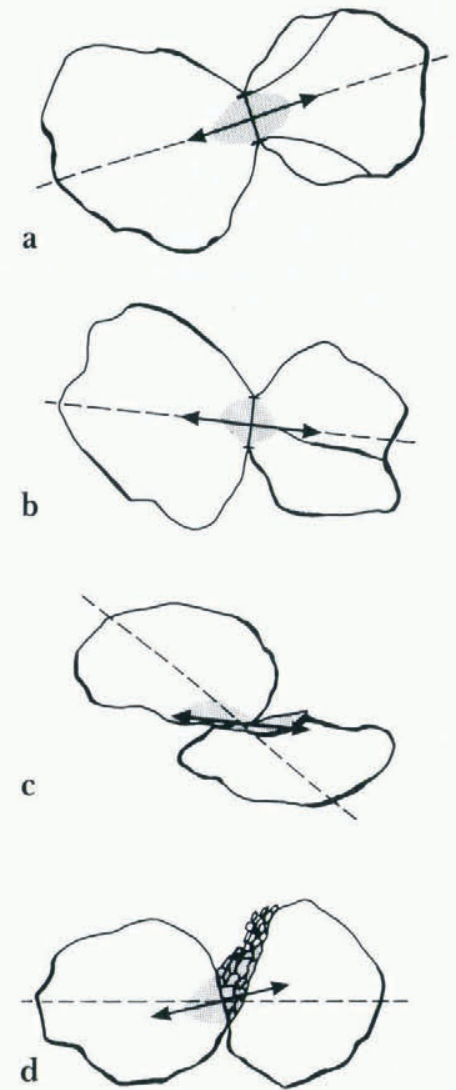

Fig. 7. Carloon, after Brzesowsky (1995), theoretically oullining the respective types of grain fracturing. Dashed lines connect "centres" of grains in contact. Arrows represent contact forces; shaded areas represent deformed contact regions. (a) Diametrical loading at low-compression rates. Ring cracks situated at the edge of the contact region pass into divergent cone cracks. (b) Diametrical loading at high compression rates. Radial fractures propagate as meridional cracks. (c) Tangential loading at high angles of incidence. Frictional sliding gives rise to occasional "chipping-off" of flakes from a grain surface. (d) Tangential loading at low angles of incidence. The process of attrition is exemplified by crushing of all or part of the grain.

stress values in which fracturing may be triggered, the presence of primary fractured grains in any considered sediment implies deformation in a subglacial environment.

More specifically, fracturing of grains may be used as an implement in deciphering glaciomarine sequences, where the technique may contribute to resolving whether sediment was tectonized by grounded ice (Drewry and Cooper, 1981; Eyles and others, 1985; Hart and Roberts, 1994; Hiemstra and others, 1996). Furthermore, the technique has future potential in deducing more specific quantitative information concerning subglacial conditions.

\section{ACKNOWLEDGEMENTS}

This work is part of a project supported by The Netherlands Geosciences Foundation (GOA), with financial aid from The Netherlands Organization for Scientific Research (NWO). Suggestions by D. Huddart and an anonymous reviewer on earlier drafts helped to improve the paper. Thanks are due to F. Backer and C. Snabilié for preparing the illustrations and to $\mathrm{C}$. Zeegers, who produced the thin sections. 


\section{REFERENCES}

Alley, R. B. 1989a. Water-pressure coupling of sliding and bed deformation: I. Water system. 7. Glaciol., 35 (119), 108-118.

Alley, R. B. 1989b. Water-pressure coupling of sliding and bed deformation: II. Velocity-depth profiles. F. Glaciol., 35(119), 119-129.

Alley, R. B., D. D. Blankenship, C. R. Bentley and S.T. Rooney. 1987. Till beneath Ice Stream B. 3. Till deformation: evidence and implications. 7. Geophys. Res., 92(B9), 8921-8929.

Benn, D. I. and D. J. A. Evans. 1996. The interpretation and classification of subglacially-deformed materials. Quat. Sci. Rev., 15(1), 23-52.

Bordonau, J. and J.J. M. van der Meer. 1994. An example of a kinking microfabric in Upper Pleistocene glaciolacustrine deposits from Llavorsí (central southern Pyrenees, Spain). Geol. Mijnbouw, 73(1), 23-30.

Boulton, G. S. 1979. Processes of glacier erosion on different substrata. 7 . Glaciol., 23(89), 15-38.

Boulton, G. S. 1987. A theory of drumlin formation by subglacial sediment deformation. In Menzies, J. and J. Rose, eds. Drumlin Symposium. Rotterdam, A.A. Balkema, 25-80.

Boulton, G. S. 1996. Theory of glacial erosion, transport and deposition as a consequence of subglacial sediment deformation. f. Glaciol., 42(140), 43-62.

Boulton, G. S. and K. E. Dobbie. 1993. Consolidation of sediments by glaciers: relations between sediment geotechnics, soft-bed glacier dynamics and subglacial ground-water flow. f. Glaciol., 39(13l), 26-44.

Boulton, G. S. and R.C.A. Hindmarsh. 1987. Sediment deformation beneath glaciers: rheology and geological consequences. 7. Geophys. Res., 92(B9), 9059-9082.

Boulton, G. S., D. L. Dent and E. M. Morris. 1974. Subglacial shearing and crushing, and the role of water pressures in tills from south-east Iceland. Geogr. Ann., 56A (3-4), 135-145.

Brewer, R. 1976. Fabric and mineral analysis of soils. Huntington, Krieger.

Brzesowsky, R. H. 1995. Micromechanics of sand grain failure and sand compaction. (Ph.D. thesis, Universiteit Utrecht.)

Dreimanis, A. 1989. Tills: their genetic terminology and classification. In Goldthwait, R. P. and C. L. Matsch, eds. Genetic classification of glacigenic deposits. Rotterdam, A. A. Balkema, 17-83.

Drewry, D. J. and A. P. R. Cooper. 1981. Processes and model of Antarctic glaciomarine sedimentation. Ann. Glaciol., 2, 117-122.

Eyles, C. H., N. Eyles and A. D. Miall. 1985. Models of glaciomarine sedimentation and their application to the interpretation of ancient glacial sequences. Palaeogeogr., Palaeoclimatol., Palaeoecol., 51 (1-4), 15-84.

Haldorsen, S. 1981. Grain-size distribution of subglacial till and its relation to glacial crushing and abrasion. Boreas, 10(1), 91-105.

Ham, N. R. and D. M. Mickelson. 1995. Micromorphology of basal till, Burroughs Glacier, Alaska. In Engstrom, D. R., ed. Proceedings of the Third Glacier Bay Science Symposium. Anchorage, AK, U.S. Department of the Interior. National Park Service, 82-86.

Hart, J. K. and D. H. Roberts. 1994. Criteria to distinguish between subglacial glaciotectonic and glaciomarine sedimentation. I. Deformation styles and sedimentology. Sediment. Geol., 91(1-4), 191-213.

Hiemstra, J. F., K. Zaniewski and J. J. M. van der Meer. 1996. Extent of the grounded Antarctic ice sheet in space and time. Circumpolar J., 11(1-2), $72-74$.

Höfle, H. -C. 1983. Strukturmessungen und Geschiebeanalysen an eiszeitlichen Ablagerungen auf der Osterholz-Scharmbecker Geest. Abh. Naturwiss. Ver. Bremen, 40, 39-53.

Hooke, R. LeB. and N. R. Iverson. 1995. Grain-size distribution in deforming subglacial tills: role of grain fracture. Geology, 23(1), 57-60.
Iverson, N. R., T. S. Hooyer and R. LeB. Hooke. 1996. A laboratory study of sediment deformation: stress heterogeneity and grain-size evolution. Ann. Glaciol., 22, 167-175.

Johnson, K. L. 1985. Contact mechanics. Cambridge, Cambridge University Press.

Mahaney, W. C., W. Vortisch and P. Julig. 1988. Relative differences between glacially crushed quartz transported by mountain and continental ice-some examples from North America and East Africa. Am. 7. Sci., $288(8), 810-826$

May, R.W. 1980. The formation and significance of irregularly shaped quartz grains in till. Sedimentology, 27 (3), 325-331.

Menéndez, B., W. Zhu andT. -F. Wong. 1996. Micromechanics of brittle faulting and cataclastic flow in Berea sandstone. 7. Struct. Geol., 18(1), 1-16.

Menzies, J. and A.J. Maltman. 1992. Microstructures in diamictonsevidence of subglacial bed conditions. Geomorphology, 6 (1), 27-40.

Menzies, J. and W.W. Shilts. 1996. Subglacial environments. In Menzies, J., ed. Past glacial environments - sediments, forms and lechniques. Vol. 2. Glacial environments. Oxford, etc., Butterworth-Heinemann, 15-136.

Morgenstern, N. R. and J.S. Tchalenko. 1967. Microscopic structures in kaolinite subjected to direct shear. Géotechnique, 17,309-328.

Morrow, C. A. and J. D. Byerlee. 1989. Experimental studies of compaction and dilatancy during frictional sliding on faults containing gouge. $f$. Struct. Geol., 11 (7), 815-825.

Murphy, C. P. 1986. Thin section preparation of soils and sediments. Berkhamstead, AB Academic.

Murray, T. and J. A. Dowdeswell. 1992. Water throughflow and the physical effects of deformation on sedimentary glacier beds. 7. Geophys. Res. 97 (B6), 8993-9002.

Rajlich, P. 1993. Riedel shear: a mechanism for crenulation cleavage. Earth Sci. Rev., 34, 167-195.

Ramsay, J. G. 1980. Shear zone geometry: a review. 7. Struct. Geol., 2(1), 83-99.

Rappol, M., S. Haldorsen, P. Jørgensen, J. J. M. van der Meer and H. M. P. Steltenberg, 1989. Composition and origin of petrographically-stratified thick till in the northern Netherlands and a Saalian glaciation model for the North Sea basin. Mededelingen Werkgroep Tertiair en Kiwartair Geologie $26,31-64$.

Sammis, C., G. King and R. Biegel. 1987. The kinematics of gouge deformation. Pure Appl. Geophys., 125 (5), 777-812.

Solheim, A. 1991. The depositional environment of surging sub-polar tidewater glaciers: a case study of the morphology, sedimentation and sediment properties in a surge-affected marine basin outside Nordaustlandet, northern Barents Sea. Nor. Polarinst. Skr. 194.

Van der Meer, J. J. M. 1987. Micromorphology of glacial sediments as a tool in distinguishing genetic varieties of till. In Kujansuu, R. and M. Saarnisto, eds. INQUA Till Symposium, Finland 1985. Espoo, Geological Society of Finland, 77-89. (Special Paper 3.)

Van der Meer, J.J. M. 1993. Microscopic evidence of subglacial deformation. Quat. Sci. Rev., 12 (7), 553-587.

Van der Meer, J. J. M. 1996. Micromorphology. In Menzies, J., ed. Past glacial environments, sediments - forms and techniques. Vol. 2. Glacial environments. Oxford, etc., Butterworth-Heinemann, 335-355.

Van der Meer, J.J. M., M. Rappol and J. N. Semeyn. 1983. Micromorphological and preliminary X-ray observations on a basal till from Lunteren, The Netherlands. Acta Geol. Hisp., 18, 199-205.

Whalley, W. B. and D. H. Krinsley. 1974. A scanning electron microscope study of surface textures of quartz grains from glacial environments. Sedimentology, 21, 87-105.

Zhang, J., T. -F. Wong and D. M. Davis. 1990. Micromechanics of pressureinduced grain crushing in porous rock. 7. Geophys. Res., 95 (B1), 341-352. 